\title{
BOSQUEJO DE LA POESIA CUBANA EN EL EXTERIOR
}

\author{
POR \\ YARA GONZALEZ-MONTES \\ University of Hawaii at Manoa
}

\section{A MODO DE INTRODUCCIÓN}

Al enfrentarnos a la tarea de hacer un estudio de la poesía cubana que se escribe fuera de Cuba, nos encontramos con un panorama mucho más extenso y complejo de lo que a primera vista parece. El hecho de que no existen estudios generales sobre la misma ni trabajos específicos sobre sus figuras representativas, nos coloca frente a un territorio virgen. En la Bibliografía crítica de la poesía cubana ', que cubre el período que se extiende de 1959 a 1971, registramos sesenta y siete autores, muchos de los cuales publican más de un libro durante esos años. Estos escritores forman un núcleo de actividad lírica digno de tomarse en consideración. Aunque no todos traspasan los límites de la versificación, una tercera parte de ellos merece ser tomada en cuenta seriamente al hablar de la poesía cubana. Si agregamos a éstos los poetas que, imposibilitados de publicar sus libros (existe una serie de dificultades editoriales con las que tienen que enfrentarse los escritores cubanos en el extranjero), se ven obligados a darse a conocer en publicaciones periódicas de efímera existencia, de 1971 a la fecha, comprobamos que el número de poetas ha aumentado considerablemente.

Tomando en consideración los estudios bibliográficos publicados posteriormente, nos damos cuenta de que, a partir de 1971, el número de autores y libros publicados se ha triplicado. Por ejemplo, en Escritores de

\footnotetext{
' Matías Montes Huidobro y Yara González-Montes, Bibliografía crítica de la poesía cubana (Madrid: Playor, 1973).
} 
la diáspora cubana ${ }^{2}$ aparecen citados más de doscientos poetas, voces nuevas muchos de ellos. El análisis individualizado de cada uno de estos autores y sus textos conducirá, lógicamente, a una valoración precisa de los mismos. Este trabajo puede ser considerado como punto de partida en el camino hacia una integral y completa interpretación de la lírica cubana durante los últimos treinta años. La historia total de la poesía cubana de este período sólo podrá lograrse haciendo un trabajo comparativo entre la producción lírica insular y la producida en el exilio, en un cotejo de los textos estadística y valorativamente, en un análisis de fondo y forma y llegándose al establecimiento de una escala de valores.

Hay un hecho innegable que no es posible soslayar: la existencia de un movimiento literario de una Cuba peregrina que se inicia en $1959 \mathrm{y}$ que ha ido creciendo y solidificándose progresivamente. Este movimiento es comparable, a pesar de sus diferencias, al movimiento literario que se produce fuera de España después de la Guerra Civil. Ignorar esto es dejar incompleto el panorama de la literatura cubana contemporánea. Ante el vastísimo paisaje lírico descrito, sólo me propongo trazar unas directrices que puedan resultar orientadoras y seleccionar algunos autores y textos representativos.

No es mi intención darle a este trabajo un carácter histórico-político, pero no es posible hablar de la poesía cubana fuera del contexto histórico dentro del cual se forma. Esto es cierto dentro y fuera de Cuba. Por razones obvias, la poesía que se publica en Cuba responde, ante todo, a pautas trazadas por la Revolución, y está de acuerdo con su espíritu y sus objetivos. Tratar de discutirla sin tomar en cuenta su contenido ideológico, es imposible. Por razones parecidas, la que se publica fuera de Cuba responde a un mismo hecho histórico, que es la antítesis del proceso. No podemos desubicarla de esa realidad porque carecería de sentido. Se origina por una circunstancia política que ocurre en 1959 y que es un factor determinante. La evidencia de este hecho histórico está presente en este movimiento poético, manifestándose de manera directa a veces, y distanciándose, en otras ocasiones, por medio de depuraciones estilísticas y transmutaciones míticas.

Hay que establecer, además, el carácter de las diferentes oleadas migratorias, ya que la naturaleza de las mismas será factor determinante en el quehacer poético. Desde el momento que comienza la ruptura territorial de los cubanos, en 1959, han sucedido varios éxodos, con características propias, que han engrosado el exilio y le han dado un carácter sui generis.

${ }^{2}$ Daniel C. Marats y Mabesma D. Hill, Escritores de la diáspora cubana (N. J.-London: Scarecrow Press, 1986). 
El primer grupo que abandona la Isla está formado, en su mayoría, por los más adeptos al gobierno pre-castrista, además de contar con intelectuales destacados, como Gastón Baquero, que sale en 1959, cuya obra trasciende todo tipo de filiación de esta índole. Le sigue el éxodo integrado por los que, ilusionados con la Revolución y colaboradores entusiastas en un principio, terminan tomando el camino del destierro. Muchos de los intelectuales más liberales de la época pertenecen a este grupo. Se inicia con Montes Huidobro en 1961, y va adquiriendo mayor fuerza con figuras como Guillermo Cabrera Infante, cuya salida de Cuba, en 1965, es una verdadera sacudida, que llegará a su clímax con la de Heberto Padilla, en 1980, y más recientemente con escritores como José Triana y César Leante. En 1980, cuando este éxodo está aún teniendo lugar, se produce el del Mariel, emigración en masa, entre cuyos escritores más conocidos se encuentra Reinaldo Arenas. Integrado por jóvenes formados intelectual y culturalmente bajo el gobierno castrista, traen al exilio, no sólo sus vivencias interiores y las experiencias de un modo de vida prácticamente desconocido para los ya residentes en los Estados Unidos, sino también su formación intelectual. Su poesía tiene que responder (incluyendo la forma lírico-musical de «La Nueva Trova» en el exilio) a cánones diferentes y a aproximaciones ideológicas radicalmente opuestas a los de la primera generación apuntada. Ellos, que se formaron bajo un sistema ideológico marxista, encuentran su complemento en un cuarto grupo formado por jóvenes educados en los Estados Unidos. Como los jóvenes del Mariel, que han vivido una realidad marginada dentro y fuera de Cuba, estos jóvenes se han desarrollado en una situación similar en este país, particularmente en Miami. Representan una nueva proyección lírica que se manifiesta de forma bilingüe. Son escritores cubano-americanos, ubicados dentro de una nueva marginación en el exilio. Finalmente, queda un quinto grupo que ha vivido un exilio diferente a todos los demás, con vivencias propias y circunstancias diferenciadoras y específicas. Son escritores que, por un número de años más o menos extenso, han estado encarcelados en Cuba, escribiendo desde allá una obra poética que se da a conocer en el extranjero. Su poesía, producto de motivaciones históricas, políticas y literarias, cae dentro de la órbita de la literatura cubana en el exterior. Estas cinco coordenadas de escritores que aparecen en nuestro esquema forman cinco trayectorias de la lírica cubana publicada en el destierro. Cada una de ellas responde a una circunstancia específica y normativa diferente. Están situadas dentro de una realidad coherente en el tiempo, representada por el hecho histórico político que la origina, y en el espacio, por Cuba como realidad territorial. Todas estas trayectorias y elementos le infunden características únicas a esta poesía. 
Pero hay que agregar otros factores no menos importantes. El exilio va adquiriendo su fisonomía por omisiones. De un lado hay que señalar las que sufren cada grupo entre sí. Del otro, las que sufren los escritores fuera de Cuba con respecto a los que están en Cuba, y viceversa. Si consideramos el fenómeno explicado en su totalidad y tratamos de distanciarnos de él, observamos que existe un sistema de complementarios. A esto hay que añadir una realidad geográfica. La Cuba peregrina se ha concentrado principalmente en Miami, centro cohesivo de la misma, núcleo aglutinador, que se ha convertido en verdadero melting pot de los diferentes grupos mencionados. La escisión y el alejamiento que han tenido lugar se van a manifestar en dos sentidos: a) dentro del tiempo transcurrido de un grupo migratorio a otro; $b$ ) dentro del espacio que separa a los grupos que ya se encuentran fuera del territorio insular de aquellos que aún no han emigrado. Esto, como es lógico, se manifiesta en la expresión lírica, que forma parte de la visión histórica.

Paul Ilie, que ha estudiado minuciosamente este fenómeno en relación con España, afirma: «puede decirse que existe una relación bilateral entre la emigración y la brecha que abre en la nación. El ciudadano ausente deja un vacío, pero la masa que rodea el vacío permanece y debe reaccionar. En ambas direcciones ha tenido lugar una privación, porque mientras el segmento extirpado está territorialmente exiliado de la tierra natal, la población residente se ve reducida al exilio interior. Cada segmento está incompleto y ausente del otro» ${ }^{3}$. Esta afirmación ayuda a comprender el desarrollo de la poesía cubana contemporánea, porque ella se construye sobre un proceso de negaciones, de vacíos, que se van sumando progresivamente. Cada grupo señalado representa una fragmentación del todo y, al mismo tiempo, una mutilación respecto a los otros núcleos. Los que se han ido están, a su vez, separados de los que, aun viviendo en la Isla, esperan abandonarla en un futuro. No es de extrañar que Ilie afirme que «el emigrado repatriado conserva una comprensión realista de su historia, mientras que el residente marginado duda por completo del realismo del pasado» ${ }^{4}$. Esto es particularmente cierto entre poetas muy jóvenes inmigrantes de la década del ochenta, que apenas han empezado a publicar en el exilio. Ellos establecen un nexo con generaciones precedentes de poetas cubanos que, habiendo dejado el territorio insular antes que ellos, les eran prácticamente desconocidos. La historia de la poesía cubana contemporánea, vista así, puede dar una idea de la magnitud del trabajo con el que

\footnotetext{
${ }^{3}$ Paul Ilie, Literatura y exilio interior (Madrid: Fundamentos, 1981), p. 10.

${ }^{4}$ Paul Ilie, Ibid., p. 114.
} 
tiene que enfrentarse la crítica. Son éstas las razones que me obligan, por el momento, a limitarme en este bosquejo.

El referido estudio de Ilie sobre el exilio español es fundamental porque establece consideraciones generales aplicables a los poetas cubanos que analizamos. No las seguiré al pie de la letra, porque no siempre se cumplen en todos sus órdenes, pero sí voy a señalar algunas categorías clasificatorias que me parecen significativas y comunes.

\section{DesarRaigo y ALIENACIÓN}

Las múltiples manifestaciones de la alienación quizá sean el fenómeno más característico que nos encontramos en la poesía que estamos discutiendo. «El temperamento desarraigado aparece tal vez más vivamente en textos literarios a través de las inquietudes de la alienación, pero es importante distinguir este tipo de alienación de las variedades marxistas y existencialista. Más que una situación económica o metafísica, el estado de ánimo del que se siente exiliado fủnciona psicológicamente como respuesta y oposición a la comunidad desconectada» ${ }^{5}$. No se trata de un estado alienatorio producido por la pérdida de la identidad dentro de la mecánica de una sociedad de consumo. Se trata de una alienación vista como una forma de exilio con respecto a la sociedad; lo que Ilie llama «sensación de pérdida social» ${ }^{6}$. La poesía de Roberto Cazorla es viva expresión de ella.

\section{PRINCIPIO DE FIJACIÓN E IRREVERSIBILIDAD}

Existe, a veces, la fijación de una identidad determinada establecida en la memoria, que puede obstaculizar la progresión histórica, y hasta la lírica. El poeta se aferra a un punto en el recuerdo como una necesidad de ser. Este principio de fijación imposibilita el entendimiento histórico, no sólo entre los escritores dentro y fuera del territorio insular, sino también entre las diferentes generaciones de autores residentes en el exterior. Sin embargo, en los poetas más auténticos implica una búsqueda de nuevos medios expresivos.

\section{Dislocamiento de LA IDENTIDAd CULTURAL Y ASIMILACión}

La identidad cultural del poeta se ve fragmentada y en crisis debido a la historia y a la nueva realidad en que vive. El estado de choque creado

\footnotetext{
5 Paul Ilie, Ibid., p. 90.

${ }^{6}$ Paul Ilie, Ibid., p. 90.
} 
por su nueva situación no siempre conduce a la asimilación. Puede ocasionar graves conflictos de identidad, como ocurre frecuentemente con los poetas cubanos más jóvenes que han crecido en un ambiente bi-cultural. En estos casos la poesía se manifiesta de otro modo, no solamente desde un punto de vista léxico, sino por una diferente percepción psicológica de la realidad.

\section{DIMENSIONES ARQUETÍPICAS Y MÍTICAS}

Todo este conjunto de factores se puede sublimizar estéticamente, surgiendo una cuarta dirección donde se hace una reconstrucción del mundo dentro de nuevos términos. El dislocamiento creado por la realidad lleva a la fabulación y se compone una mítica que representa una escala ascendente en el quehacer poético.

Estas cuatro directrices aparecen presididas por tres autores formados antes de que el movimiento de la diáspora cubana tuviera lugar, y que vamos a discutir primeramente: Agustín Acosta, asociado a la creación de arquetipos tradicionales; Eugenio Florit, que se caracteriza por la estilización y decantamiento estéticos, y Gastón Baquero, cuyo proceso de mitificación conduce a la creación de arquetipos últimos.

Agustín Acosta nace en Matanzas en 1896, sale de Cuba en 1972 y muere en Miami en 1979. Publica dos poemarios fuera de la Isla: El Apóstol y su Isla y Trigo de luna. Es obvio que su obra está hecha cuando llega a los Estados Unidos, pero su importancia no debe soslayarse. Acosta es portador del título de Poeta Nacional de Cuba y se le considera como la figura que incorpora a Cuba al modernismo con su libro Ala, donde «se manifiesta predominantemente como cultivador de esa poesía en que 1o ornamental, lo musical y lo rítmico tienen un valor superior»? Al referirse a poemarios posteriores, Aldo Ramón Fores señala, conjuntamente con la preocupación social y la protesta, el intimismo, las consideraciones filosóficas, existenciales y religiosas, el nacionalismo y el patriotismo como sus rasgos más representativos. En su obra nos encontramos con un arquetipo de la lírica cubana, «intérprete fiel de su pueblo» y «cantor de los sentimientos más arraigados en el espíritu nacional» ${ }^{8}$. Resulta lógico que su poesía sea la expresión de una fijación establecida en la memoria. Esto acrecienta un principio de irreversibilidad mediante el cual Cuba es vista en un momento anterior, prefijado en el recuerdo por los valores antes señalados. En ocasiones es una poesía que mira hacia atrás en su estética,

\footnotetext{
${ }^{7}$ Aldo Ramón Fores, La poesía de Agustín Acosta (Michigan: Ann Arbor, Xerox University Microfilm, 1976), p. 274.

${ }^{8}$ Aldo Ramón Fores, Ibid., p. 277.
} 
pero que en muchos poetas cubanos fuera de la Isla terminará evolucionando y actualizándose dentro de otros cánones.

En un ámbito geográfico-histórico diferente, oponiéndose a la anterior, aparece la poesía de Eugenio FloRIT. Su universo poético es de otra naturaleza. Aunque nacido en España en 1903, por su formación y trayectoria literaria forma parte integral de la lírica cubana. Florit no abandonó la Isla por motivos políticos; sin embargo, su asociación con los poetas cubanos exiliados es muy estrecha, particularmente en años recientes, al trasladarse a Miami. Considerado como «maestro», denominación que insiste en negar, es admirado particularmente por los poetas de las nuevas promociones. Su importancia en el exilio es sintomática. Cabe indagar los motivos de la misma. En oposición al ámbito concreto de la línea de Acosta, Florit trasciende la realidad para proyectarse en un espacio puro. El proceso de refinamiento gradual que se observa en su poesía le da una delicadeza especial a la misma. En el poema «La poesía», del libro Castillo interior y otros versos, uno de sus más recientes poemarios, el poeta, muy a su modo, la define:

Una rama de aire que se mece a la pausa del viento verdadero, hecha de dulce resonar y de armonioso pensamiento.

$\mathrm{Y}$ un aire antiguo. (Pero dime dime dónde estarás cuando vaya a buscarte por ese caminito que va a ninguna parte.)

Y una voz en el árbol del olvido ${ }^{9}$.

Tomando una imagen de la naturaleza, «rama que se mece al viento», asistimos a la demiúrgica transformación de la misma en sustancia poética. La rama es de «aire», «hecha de dulce resonar» y «armonioso pensamiento». El primer elemento le da carácter irreal y etéreo; el segundo, le infunde el ritmo al que también contribuye la «pausa» de ese viento «verdadero» que la mece; el contenido es la base que la sostiene. Después agrega un elemento más: «el aire antiguo», tradición poética de todos los tiempos. La lectura del poema se desliza suavemente y sin obstáculos; pero, de pronto, abruptamente, surge un paréntesis que nos saca de la definición, y con ese tono coloquial tan suyo, lleno de una tierna emoción, parece dirigirse a la misma poesía cuando le pregunta: «dónde estarás cuando

\footnotetext{
${ }^{9}$ Eugenio Florit, Castillo interior y otros versos (Miami: Ultra Graphics Corporation, 1987), p. 31
} 
vaya a buscarte / por ese caminito que va a ninguna parte», colocándose en un futuro fuera del espacio poético en que ha ido desarrollando su definición. El insistente uso del imperativo del verbo «decir», que denota la impaciencia del que cuestiona, unido al diminutivo «caminito», le dan una nota de ternura infantil al verso. La pregunta queda sin respuesta, y en la digresión mental, tan inocente al parecer, Florit está introduciendo en el poema una angustiosa pregunta existencial, pero con una transparencia lírica que se superimpone a los contenidos existencialistas. La palabra omitida, muerte, llega a nosotros como un instantáneo relámpago para permanecer presente en el último verso gracias al término «olvido»: voz en el olvido, voz en la que se pierde el recuerdo, voz que ya no está.

Aunque en la poesía de Florit existen connotaciones existencialistas y en Castillo interior hay poemas religiosos cercanos a la mística, lo que predomina en ella es la creación de un espacio puro. Este espacio que podríamos calificar de anti-espacio es un ámbito onírico donde el poeta desarrolla una ensoñación estética. El poeta vuelve a la tradición mística e impone en su poesía una armonía que es clásica y que tiene su origen en Garcilaso de la Vega. Cabría preguntarse ahora, después de apuntadas estas características, cuál es el nexo de Florit con un conjunto de poetas del destierro que viven en un proceso de desajuste que va de la alienación a la asimilación. Tal vez sea porque Florit, por contraste, produce una liberación de la angustia gracias a su lírica. En ella se encierra un anhelo pausado de comunicación con Dios. La belleza y armonía de sus versos nos conducen a un equilibrio clásico. Su poesía nos lleva a un punto anterior al éxodo, a una fijación en la tradición clásica española, que logra calmar la desesperación y la angustia. Lejos de toda asimilación y de todo dislocamiento de la identidad cultural, ofrece un áncora salvadora al nutrirse en las raíces más puras de la tradición hispánica. Alejada de la realidad inestable, se reafirma en un espacio propio hacia el que dirigen su mirada otros poetas del exilio.

El tercer integrante de esta trilogía de poetas, GASTÓN BAQUERO, afirma en el prólogo a Magias e invenciones que «la poesía es la fantasía, la lectura que completa ante nuestros ojos la desnudez (la realidad) de lo existente. Dar existencia a lo tenido hasta ese momento por inexistente es la función mayéutica de la poesía... Lo único que me ha interesado en ese viaje hacia el morir que es estar vivo, es inventar, fabular, imaginarle a una realidad cualquiera la parte -el completo- que creía le faltaba. No ignoro la soberbia que hay en esto, pero la soberbia es también un instinto indomable» ${ }^{10}$. El reino poético de Gastón Baquero no es, efectivamente,

\footnotetext{
${ }^{10}$ Gastón Baquero, Magias e invenciones (Madrid: Cultura Hispánica, 1984), pp. 11-12.
} 
el de este mundo, y esa parte que fabula, con la que completa la realidad, no tiene, en modo alguno, el carácter de la recreación de Florit. Sus maravillosas fábulas describen un mundo fascinante en un ambiente irreal en donde el tiempo de la historia desaparece dentro del absoluto que es el tiempo. Y es que Baquero, como creador de magias, es, lógicamente, un mago que, como el sabio Anaximandro de su «Coloquial para una elegía», es un profundo conocedor de los secretos del tiempo. El poeta lo contempla, como el sabio, desde fuera, distanciándose de su momento vital. De esta manera adquiere una perspectiva muy particular que le permite calibrar en toda su magnitud la tragedia del tiempo: "Only if the life span of the individual were identical with that of mankind could he participate in the human development which occurs in the historical process... Of this contradiction between what he could realize and what he actually does realize, he has, at least, a dim perception» ". Pero Baquero, consciente de esa y otras contradicciones que dominan la humana existencia, fabula para, al menos en el mundo de la poesía, encontrar consuelo a esa dicotomía existencial de la que no puede liberarse. El poeta reconoce las limitaciones del tiempo real formado por la historia:

El tiempo necesita millones de años inventados por el hombre

para consumar siquiera un segundo de su existencia pura.

\section{y todos los hombres y mujeres, y los episodios que llamamos «la historia», caben holgadamente en la minúscula fracción de una millonésima de segundo ${ }^{12}$.}

Baquero crea verdaderos mitos que son la historia del ámbito poético, que sí domina, y apoyado en sus «ojos arcánicos», se da a la tarea de crear sus propios orbes, donde cotidianeidad y magia se complementan. Como el Baron Humperdansk de su «Brandeburgo 1526», que desde Brandeburgo puede contemplar la tierra «en cuya realidad creían tan sólo los navegantes fieles a Juan de Mandavilla» ${ }^{13}$, Baquero viaja por sus propios paisajes de fulgor y diamante:

\footnotetext{
$"$ Erich Fromm, Man for himself (New York: Ballantine Books, 1984), p. 51

${ }^{12}$ Gastón Baquero, Ibid., pp. 42-43.

${ }^{13}$ Gastón Baquero, Ibid., p. 24.
} 


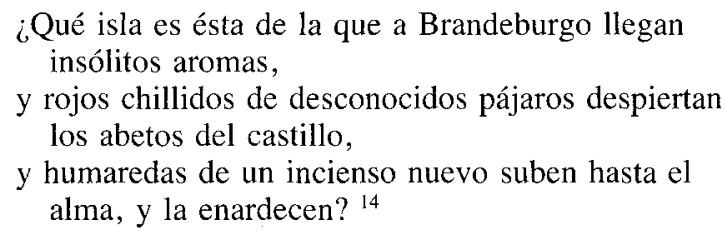

Tiempo y distancia se borran en la poesía de Baquero, e identificando al poeta con el personaje de su poesía, podemos decir que «having lost paradise... he has become the eternal wanderer (Odysseus, Oedipus, Abraham, Faust); he is impelled to go forward and with everlasting effort to make the unknown known by filling in with answers the blank spaces of his knowledge. He must give account to himself of himself, and of the meaning of his existence» ${ }^{15}$. Consciente de sus limitaciones, en relación con el tiempo y con la historia, el poeta crea un nuevo paraíso en el que re-crea una nueva historia y una isla diamantina. Observa, como el Barón Humperdansk, en la distancia, el lejano paraíso; el mismo que tiene al alcance de la mano en la página escritá, aquél en donde se canta(ba):

Senserení, color de agua en la mano, y sabor de aleluya en bandeja de plata; Senserení cantando a través del verano, con su pluma de oro y su pico escarlata ${ }^{16}$.

Es evidente que un poeta como Baquero es representativo de una escala ascendente, donde se supera el nivel primario de la realidad. A través de ella llega, mediante la fabulación y la creación de su propio mundo, a los arquetipos míticos que se independizan de las limitaciones históricas. Es por eso que la mitificación es la escala última de un proceso ascendente de la lírica cubana en el exterior. En primer término, es una escapatoria que acaba siendo una solución. En este proceso, desarraigo y alienación, dislocamiento de la identidad cultural y asimilación, quedan superados. Baquero da una cuerda fundamental en la que hay que seguir indagando.

Teniendo en cuenta las oleadas migratorias de la diáspora cubana y el significado arquetípico de Acosta, Florit y Baquero, retomemos los cuatro puntos que nos parecen directrices fundamentales.

\footnotetext{
${ }^{14}$ Gastón Baquero, Ibid., p. 24.

15 Erich Fromm, Ibid., p. 50.

${ }^{16}$ Gastón Baquero, Ibid., p. 26.
} 


\section{Desarraigo y alienación}

Para Serrano Poncela, el exiliado se encuentra «arrancado de su materia alimenticia, su paisaje y su mundo circundante, obligado a asimilar desde el aire una realidad siempre foránea». Sometido a un nuevo «ritmo histórico», sus problemas «permanecen dentro, enconados, pidiendo salir de algún modo», desgarrándose entre «la evasión y la acción» ${ }^{17}$. La situación descrita tiene que conducir necesariamente a un estado alienatorio que se hace muy desolador. En el fondo, él quisiera actuar en conjunción con el mundo, pero, dadas sus circunstancias, no puede. Se produce entonces un desgarramiento entre el individuo y la historicidad. El poeta se convierte en un agonista, en un existencialista que grita su verdad dándose cuenta de que nadie lo oye. El desarraigo produce la más enajenante de las circunstancias. Es difícil encontrarse con algún poeta cubano de los estudiados que no exprese, en mayor o menor medida, esta característica. Uva Clavijo, José Corrales, Mauricio Fernández, Rita Geada, José Kozer, Mireya Robles, Teresa María Rojas, Pío Serrano y otros muchos forman una larga lista de poetas que manifiestan diferentes niveles de alienación.

Roberto CAZorla es, en este sentido, un poeta representativo. En él, la «sensación de pérdida social», en palabras de Ilie, produce una fuerte descarga lírica. Los títulos de sus libros más recientes: Esta calle mundial de indiferencia y El mundo es una misa para sordos, sirven para colocar al poeta en la agobiante situación de un individuo que realiza un ritual («misa»), que es también voz comunicante y acto poético, enfrentándose con «la calle mundial de indiferencia» por donde transita un auditorio de «sordos». De esa manera establece, desde los títulos de sus poemarios, su desarraigo y alienación.

En 1981 publica Cazorla Esta calle mundial de indiferencia, en cuyo prólogo afirma: «Lo más hermoso que me hubiera podido ocurrir es el no haber tenido que escribir este libro» ${ }^{18}$. Y es que Cazorla es poeta que cala profundamente en los estratos sociales de nuestro tiempo y observa que el hombre, como ente individual, no cuenta para nada en el mundo de hoy, asumiendo, por consiguiente, una visión alienatoria con respecto a la realidad social. Cazorla está observando constantemente el enfrentamiento hombre-mundo, viendo al primero atrapado entre poderosas fuerzas que se encuentran fuera de su control: la política internacional de las grandes potencias disputándose la supremacía mundial; el materialismo dominante;

17 Segundo Serrano Poncela, «La novela española contemporánea», La Torre, I (abril-junio, 1953), p. 117.

${ }_{18}$ Roberto Cazorla, Esta calle mundial de indiferencia (Madrid: La gota de agua, 1981), p. 23 . 
las relaciones humanas, regidas por la hipocresía, el odio y la violencia. Su poesía se nutre del choque del individuo con la conciencia colectiva. El poeta no puede permanecer ajeno a esta situación y levanta su voz para denunciar la realidad social que hubiera deseado no vivir y no re-vivir al convertirla en sustancia de su poesía. Víctima de las circunstancias históricas y sociales del mundo actual, Cazorla se siente acorralado por una sociedad indiferente que trata de amordazarlo. Su impulso es hacia el mundo, pero éste lo rechaza, con lo que se produce un estado enajenante. Queriendo sobrevivir, grita su verdad a los cuatro vientos, y sostiene una lucha a brazo partido con la oficialidad de turno para no dejarse silenciar, ya que eso representaría su muerte. «Si se nos ahogara» es un poema que responde a estos planteamientos:

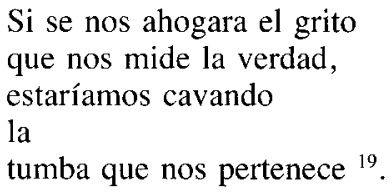

A la condicionalidad de la primera cláusula le sigue la inevitabilidad trágica de la segunda. El «grito» emitido establece un espacio auditivo al que le corresponde el vocablo «verdad», que es la medida ética del propio grito. La eliminación de esta imagen por la condicional que da título al poema lleva a un espacio reducido y descendente, que es un absoluto del silencio (tumba). La dinámica del poema surge de las tensiones opuestas latentes en el mismo. Los elementos verbales encierran un mensaje donde Cazorla advierte los peligros de la abulia y la indiferencia. Sus brevísimos poemas son relámpagos estremecedores en la conciencia del lector. $\mathrm{Al}$ adoptar esta posición de denuncia el poeta se aleja de los demás que adoptan una actitud indiferente ante los hechos que él se niega a aceptar. Señala como única solución posible la verdadera amistad, entendida como hermandad casi utópica en la que el hombre debe darse generosamente a sus semejantes, en lo mejor de sí mismo, renunciando a todo tipo de egoísmo.

Su libro más reciente, El mundo es una misa para sordos, publicado en 1986, contiene los mismos postulados del poemario comentado, existiendo entre ellos una absoluta unidad temática. La alienación del poeta ha ido en aumento. Sus padecimientos y frustraciones van dejando una huella indeleble en su espíritu. Se nos presenta en trágica imagen surrealista:

\footnotetext{
${ }^{19}$ Roberto Cazorla, Ibid., p. 30.
} 
¿Y qué hago con este yo

que se me ha suicidado entre los brazos? ${ }^{20}$

La duplicidad de la imagen del yo, que por una parte aparece muerto por un suicidio voluntario, y por otra, sin haber podido evitar la propia inmolación, el acto violento, produce el desconcierto.

Como fondo de su angustia se encuentra la ciudad de Madrid. La muerte es también una constante en sus poemas: «Pisamos / encima de un cementerio de sonrisas» ${ }^{21}$. Los rasgos humanos individualizados parecen borrarse en medio de una ciudad foránea que confirma su desarraigo: «Madrid / es una bocanada de humo maldecido, / de gentes que vinieron con el perfil borrado» ${ }^{22}$; rostros que parecen haberse desprendido de los lienzos de un Magritte o un Chirico. La naturaleza se vuelve también enemiga del hombre; la lluvia es vista como «armazón de látigos / cayendo desde el cielo» ${ }^{23}$. Es un enfrentamiento con lo inmediato. El poeta está constantemente rechazando la circunstancia de la ciudad en que vive. Su poesía está poblada de imágenes que van contra el espacio concreto de su quehacer cotidiano. Pero ese encono se sublimiza con el recuerdo, que es también parte de la fenomenología de la alienación. Vuelve entonces al pasado, que es una corriente subyacente en su poesía, su «ser niño para siempre» ${ }^{24}$. Su intensa añoranza por el tiempo ido lo lleva al deseo de percibir una sensación olfativa, una contradicción del espacio geográficonatural, una reubicación que es un imposible. Surge la imagen lírica que clama por una mañana madrileña que tenga «olor a humedad de platanales» ${ }^{25}$. El resultado es una imposibilidad lírico-psicológica que se manifiesta en la psiquis del poeta:

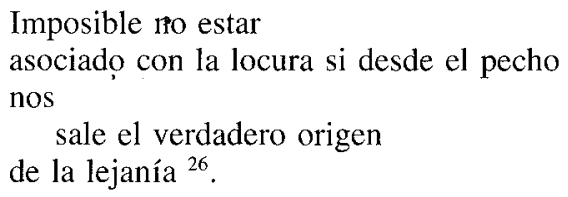

Como ha dicho Serrano Poncela, el poeta exiliado que es Roberto Cazorla se encuentra «arrancado de su materia alimenticia». Su obsesión

${ }^{20}$ Roberto Cazorla, El mundo es una misa para sordos (Madrid: La gota de agua, 1986), p. 20.

${ }^{21}$ Roberto Cazorla, El mundo... Ibid., p. 42.

22 Roberto Cazorla, El mundo... Ibid., p. 58.

${ }^{23}$ Roberto Cazorla, El mundo... Ibid., p. 35.

${ }^{24}$ Roberto Cazorla, El mundo... Ibid., p. 53.

25 Roberto Cazorla, El mundo... Ibid., p. 53.

${ }^{26}$ Roberto Cazorla, El mundo... Ibid., p. 47. 
lo conduce a un estado enajenatorio que no tiene solución inmediata en esa «calle mundial de indiferencia», donde el poema es «una misa para sordos». Ese conflicto insoluble está expresado en una contradicción poética en las oraciones que dan título al poema que cierra Esta calle mundial de indiferencia, «Así me voy, así me quedo», donde exclama:

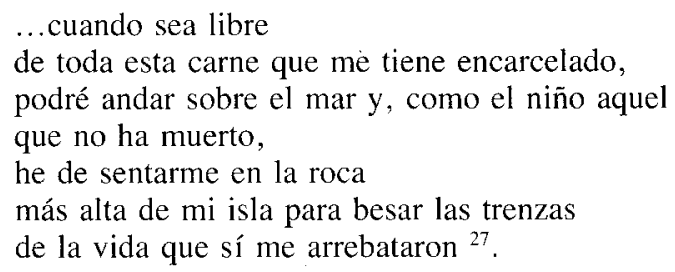

El hombre, desdoblado en el niño que aún vive en él, regresa, conciliando las antinomias del «me voy» y del «me quedo». Este conjunto de imposibilidades que caracterizan la poesía de Roberto Cazorla, sólo puede resolverlo el poeta en el acto demiúrgico-lírico descrito en el poema: retorno al pasado desde un futuro no vivido aún, acto de desesperación y al mismo tiempo de esperanza, único medio que encuentra para buscar un asidero entre la alienación y el desarraigo.

\section{Principio de fijación e irreversibilidad}

En el exilio, el poeta puede vivir y expresarse con referencia al punto en el pasado que marcó su separación histórica y geográfica de su tierra natal. Pero, inclusive, «cuando el paso del tiempo cicatriza su herida, su trasplante llega a parecerse a una cicatriz indeleble» ${ }^{28}$, que se manifiesta en la fijeza del recuerdo que aflora constantemente en su lírica. La historia, sin embargo, es irreversible y la rememoración se va haciendo cada vez más difusa, lo que puede comprobarse al producirse «una fisura en la corteza aparente del tiempo a través de la cual se ve que la memoria no guarda lo que pasó» ${ }^{29}$. Pero, de todos modos, el recuerdo permanece, y el poeta trasplantado vive una experiencia similar a la que vivieron los poetas españoles exiliados; para ellos, «ciudades, pueblos, paisajes, todo adquiría ahora otro relieve, visto desde lejos y con perspectiva diferente. A veces eran las cosas más pequeñas, los detalles nimios, los que asumían

\footnotetext{
27 Roberto Cazorla, Esta calle... Ibid., p. 112.

28 Paul Ilie, Ibid., p. 107.

29. Juan Marsé, Si te dicen que caí (México: Ed. Novaro, 1973), p. 148.
} 
de repente significación insospechada. El redescubrimiento de lo propio necesita, al parecer, el contraste con lo ajeno» ${ }^{30}$. Surge así una poesía comprometida, política, patriótica, nacionalista y paisajista, que es una de las respuestas a la poesía revolucionaria que se hace en la Isla. Se produce, inclusive, como en el caso de Luis Mario, en Miami, una poesía de temas actuales y tradicionales muy directamente dirigida a la comunidad.

Fijación e irreversibilidad pueden llegar a producir excelentes frutos cuando se buscan los adecuados medios formales. Un buen ejemplo es el caso de los «haikus» de ANA ROSA NúNEZ, donde los componentes del paisaje cubano, como el sinsonte y la palma, acercan lo tradicional a imágenes en las fronteras de lo surrealista. En el caso de LUCAS LAMADRID, como diría Ilie, «la creencia de que 'mañana volveré' se queda rezagada como una coordenada sublimal en la existencia del emigrado» y «el paso del tiempo se prolonga, reduce la posibilidad del regreso y aumenta la sensación de angustia» ${ }^{31}$. La intensidad de la memoria se superimpone al presente, donde se desintegra:

Hay memorias antiguas
me gritan desde adentro
como fieras que acosan
mi voz deshilachada ${ }^{32}$.

Y de la misma cuerda es la poesía de PABlo Le Riverend, donde la obsesión de la memoria se hace patente de modo patriótico y simbólico.

Esta fijación también juega un papel importante en poetas de otro carácter, como ocurre con HEBERTo PADILLA. En el poema que inicia $E l$ hombre junto al mar hay una afirmación del presente y un intenso deseo de borrar el pasado, como si se deseara un renacimiento en el recuerdo:
Lo mejor es que empiece a cantar desde ahora
la alegría de los sueños cumplidos y me olvide del mundo de mis antepasados. Ellos a la ceniza. Yo a la vida ${ }^{33}$.

El deseo de hacer tabula rasa del pasado lo coloca aparentemente en una posición contraria a otros poetas. Sin embargo, el mismo no será permanente y el recuerdo volverá a invadirlo, como a ellos, acompañado

\footnotetext{
${ }^{30}$ Juan Marsé, Ibid., p. 346.

${ }^{31}$ Paul Ilie, Ibid., p. 107.

${ }^{32}$ Lucas Lamadrid, Cantos de la tierra y el hombre (Miami: Al's Graphics, 1982), p. 5.

${ }^{33}$ Heberto Padilla, El hombre junto al mar (Barcelona: Seix Barral, 1981), p. 7.
} 
del anhelo de retorno. En estos poemas, al borrar el mundo de sus antepasados, está dándole un carácter ahistórico a su propia vida. No quiere retener en su memoria elementos personales, «históricos», de su biografía. Es significativo que cierre el poema con la siguiente afirmación:

$Y$ hay que exaltar la vida, sin embargo, apartar la basura, y cantar la alegría de los sueños cumplidos, pero con buena música de fondo; de violín, si es posible, que es el instrumento adecuado: agudo, recto como un arma ${ }^{34}$.

El poema mira hacia adelante, y el violín, transformado en arma, le infiere repentinamente un carácter bélico y combativo. Pero en su «Canción del hijo pródigo», Padilla mira hacia atrás, anhelando niñez y retorno:

Devuélveme el escándalo del sol la puerta del colegio

Mójenme ya los labios

con mi esponja de niño

Devuélvanme el crujido

de los árboles verdes

y el noble mar de siempre ${ }^{35}$.

El vacío de su presente vuelve a llenarse de memoria, del sentir del pasado. Los elementos naturales, sol, árboles y mar, pueblan su recuerdo; temas de nuestra poesía más tradicional expresados ahora en otros términos.

No es de extrañar, por ello, que poetas más jóvenes respondan de parecida manera. En Las catedrales del agua, de EDITH LLERENA, gran número de poemas están dedicados a la rememorización, dando lugar a un desplazamiento del presente. El ayer emerge en el espacio poético. Sus versos ofrecen la visión de una realidad transformada por la ensoñación. Isla, ciudades, paisajes y vivencias, que han permanecido en su mundo interior, afloran en su lírica:

Isla de eucalipto y colibríes,

casa de los azules,

negación de la Inmanencia.

La liturgia de tus atardeceres, salvada en el arca del recuerdo ${ }^{36}$.

\footnotetext{
${ }^{34}$ Heberto Padilla, Ibid., p. 8.

${ }^{35}$ Heberto Padilla, Ibid., p. 67.

${ }^{36}$ Edith Llerena, Las catedrales del agua (Madrid: Playor, 1981), p. 47.
} 
Esta temática puede llevar hacia una profunda expresión psico-poética de la fijación de la memoria, como pasa con «Primera casa», de LuIS GonZÁlEz-Cruz, que aparece en su libro Disgregaciones. En este poema, el poeta comienza describiendo, con delicada gracia, el mundo infantil; pero a medida que nos adentramos en su hilo narrativo, perfiles trágicos se van anunciando. Primero es la llegada del carpintero, que va tapiando los nidos de las golondrinas; luego El Hombre llega con sus rifles. Finalmente, la casa se incendia y otra nueva se edifica en su lugar. Sin embargo,

.. las alas del niño ausente
con los brazos en cruz
ardieron también junto a los cuerpos
de aquellas golondrinas prisioneras ${ }^{37}$.

La infancia ha terminado, pero no de una manera natural y progresiva, sino en forma violenta y abrupta. De esta manera, lo que es para los poetas cubanos en el destierro el incendio de la «primera casa», permanece en la psiquis colectiva de nuestra lírica.

\section{Dislocamiento de la identidad cultural y asimilación}

Al verse el escritor trasladado a un país que, aunque lo acoja generosamente, le resulte ajeno en costumbres, cultura y valores espirituales, se produce un choque y un dislocamiento interior que va a manifestarse en su creación. Eso explica que Rita GEADA nos hable de una nueva Babel; que OrLando RodrígueZ Sardiñas le cante a Langston Hughes y recorra Liverpool; que Matías MonTES Huidobro traspase la casa victoriana de Miss Strangeworth en Meadville, Pa.; que Pío SERRAno escriba sobre el reloj Baby Ben de Westlox; que Uva CLAvIJO recorra la ruta 95 sur y que José CORRALES se vuelva bilingüe cuando Elvis Presley muere a los cuarenta y dos años. El individuo va poco a poco descubriendo un nuevo mundo, que rechaza en gran parte, que no puede asimilar del todo. En los autores estudiados no se produce un proceso de asimilación, sino de desarticulación. Otros poetas, como Eliana Sú́rEZ-RIVERo, quedan asimilados por identificación con movimientos de una determinada orientación dentro del contexto norteamericano. En su caso, con el movimiento feminista:

${ }^{37}$ Luis González-Cruz, Disgregaciones (Madrid: Catoblepas, 1986), p. 16. 


\section{Gloria \\ a tantas mujeres ignoradas \\ como lo eran siempre en un principio \\ como no lo serán de ahora en adelante ${ }^{38}$.}

Sin embargo, gradualmente va surgiendo una generación de voces nuevas de poetas más jóvenes que adoptan una posición definitivamente bilingüe, como OMar Torres en Nueva York y Jorge J. RodrfGuez-FloRIDO en Chicago. A ellos hay que agregar los poetas de generaciones completamente formadas en Estados Unidos, como WALTER DE LAS CASAS y Ricardo PaU Llosa. Las listas de los autores que van del choque y dislocamiento cultural a la asimilación son extensas. La clave de estos poetas está, principalmente, en el dominio de dos idiomas, que les permite expresarse perfectamente tanto en inglés como en español.

Quizá sea Gustavo Pérez Firmat uno de los poetas más representantivos de este nuevo grupo. Nacido en La Habana en 1949, Pérez Firmat viene a los Estados Unidos en 1960, pasando a residir en Miami Su poesía bilingüe es tan interesante en un idioma como en el otro. En «D :dication» pone de manifiesto, de forma paradójica, pero que se explica por sí „nisma, su encrucijada lírica y vital:

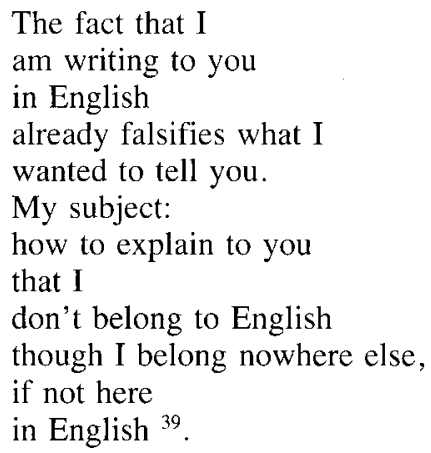

Sus poemas en español son igualmente expresivos de un desajuste, que indica que en definitiva el exilio ha conducido a un dislocamiento cultural, pero no a la asimilación. El desequilibrio manifestado en la incongruencia intencional que hay en sus poemas hace que, a pesar de que domina los dos idiomas, no pueda quedar integrado a ninguna de las dos culturas:

\footnotetext{
${ }^{38}$ Eliana Suárez Rivero, Revista Chicano-Riqueña (Vol. XI, núms. 3-4, 1983), p. 38.

39 Roberto Durán, Judith Ortiz-Coper y Gustavo Pérez-Firmat, Triple Crown (Arizona: Bilingual Press, 1987), p. 127.
} 
Call these poems a son-sequence:

Son as plural being.

Son as rumba beat.

Son as progeny ${ }^{40}$.

El grupo de poetas representado por Pérez Firmat hubiera podido ser la etapa final de la historia de la poesía cubana en el exterior hoy día. La lírica se asimilaba lingüísticamente mediante la experimentación verbal bilingüe ya señalada. Sin embargo, al tener lugar la inmigración de Mariel, en la década del ochenta, y el arribo de numerosos ex prisioneros políticos, muchos de ellos poetas desconocedores del idioma inglés, se interrumpe el proceso. El movimiento poético se revitaliza con nuevas perspectivas, voces y lenguaje, y un nuevo ciclo lírico-histórico comienza.

\section{Dimensiones arquetípicas y míticas}

Lenguaje, Mito, Dios y Hombre, con mayúsculas, podrían considerarse cuatro directrices en la búsqueda de arquetipos. Todo el conjunto de factores señalados lleva a los poetas a la necesidad de buscar ciertos arquetipos que, en algunos casos, conduce a la formulación de principios teóricos que les sirven de norma creadora. Algunos de ellos encuentran en el lenguaje en sí mismo su fórmula arquetípica. OCTAVIO ARMAND trata de vaciar los signos verbales de su significación y darles una autonomía propia, intentando una verdadera rebelión de la escritura. La escritura como «erizo» viene a ser su arquetipo, que él explica mejor que nadie: «El orden es el orden. Lo dicho se reduce a lo que se iba a decir y lo que se iba a decir se reduce a lo indecible: una mudez como de objeto que no obstante y por ello mismo permite comprobar la materialidad del discurso» ${ }^{41}$. RAFAEL CATALÁ busca su fórmula arquetípica en la ciencia-poesía, y la complejidad de algunos de sus textos queda aclarada en los prólogos que los acompañan: «La teología de la liberación, cuyo máximo exponente es el teólogo peruano Gustavo Gutiérrez, es una contribución de Hispanoamérica a la cultura universal, comparable a la física quántica y la teoría de la relatividad» ${ }^{42}$. Otros poetas, sin embargo, mucho más modestos, como ORLANDO GONZÁLEZ-ESTEVA, se conforman con arquetipos menos ambiciosos. En su libro Mañas de la poesía, González-Esteva revive una poesía popular, en la que la nostalgia de su tierra se expresa en el elemento formal

\footnotetext{
${ }^{40}$ Roberto Durán, Ibid., p. 160.

4! Octavio Armand, With Dusk (Colorado: Logbridge-Rhodes, Inc.), p. 24.

${ }^{42}$ Rafael Catalá, Ciencia poesía (Minnesota: Prisma Books, Inc.), p. 25.
} 
donde se materializa su palabra poética: la décima. Entretejida al verso aparece el «disparate lírico», elemento ya presente en la lírica cubana desde el siglo XVIII. Utilizando asociaciones inconscientes e imágenes inesperadas, González-Esteva realiza una originalísima renovación del vehículo lírico más popular y tradicional de la poesía cubana de todos los tiempos:

Ah, la oscura enredadera
del oráculo imprevisto.
La pasión por donde avisto
el corazón de la fiera.
La plenitud agorera
donde reina un dios distante,
voz de pálido semblante
que de repente se avisa
y como un rayo de tiza
desaparece al instante ${ }^{43}$.

Hacia la primera parte de este trabajo nos detuvimos brevemente en la fabulación mítica de Gastón Baquero, seleccionándolo como arquetipo poético en la «magia» e «invenciones» de la fabulación. Retomamos la mítica ahora con Juana Rosa Pita, en sus Viajes de Penélope. No se nos esconde la importancia que tiene en nuestra poesía lo afrocubano, que es todo un mundo mitológico en sí mismo y cuyas fronteras, por falta de espacio, tengo que dejar para otro momento, aunque sí debo señalar que le corresponde a PURA DEL PRADO una de las re-creaciones más sólidas que, en esta dirección, encontramos en la poesía cubana contemporánea.

Empecemos por decir que Viajes de Penélope, de Juana Rosa Pita, no es sólo la recreación de un mito. Juana Rosa Pita se posesiona del mismo, lo hace suyo, es ella misma Penélope. «Me ha dado por creerme Penélope...», dice, para distanciarse después en un condicional que acepta de antemano la imposibilidad del hecho: «Si yo fuera Penélope...» ${ }^{44}$. Con una poesía intimista, de intenso lirismo, cuidadosa en la forma, nítida en la expresión, la autora nos va contando, en los cincuenta y cinco poemas de este poemario, una historia viva en donde los niveles mítico y anecdótico se van entretejiendo en un mundo dominado por el amor. Mujer, soledad y muerte son motivos temáticos constantes del mismo. Lo anecdótico se va desarrollando dentro de un tiempo interior o psicológico en que Juana Rosa Pita aparece fuera del tiempo y, a la vez, sumergida en él. La nostalgia de un pasado ya ido, la persistencia de un ayer presente en su memoria,

\footnotetext{
${ }^{43}$ Orlando González-Esteva, Mañas de la poesía (Miami: Ultra Graphics Corp., 1981),

44 Juana Rosa Pita, Viajes de Penélope (Miami: Solar, 1980), p. 15.
} p. 12. 
la inducen a querer conservarlo, guardarlo y protegerlo del devenir que conduce al olvido; pero Penélope se reconoce como vencedora del tiempo:

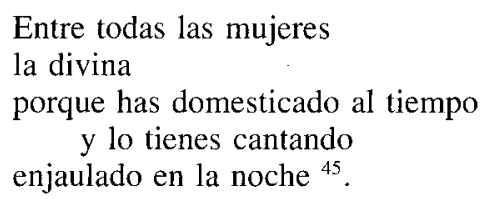

Ese tiempo prisionero en su recuerdo es re-creado en el cristal azogado de su propia memoria. La única manera posible de dominarlo es rememorándolo, re-viviéndolo, haciéndolo tan real que logre, al evocarlo con las fuertes marejadas del recuerdo, sumergir el presente, borrar los límites del tiempo. Pero al borrar los límites del tiempo se borran también los perfiles de la historia. Cuando dice: «Este que fuera cuento es vida en mí / y de una cierta isla hará la historia» ${ }^{46}$, pasado y presente se confunden. Los límites entre historia y realidad se vuelven imprecisos, de la misma manera que la autora es o deja de ser Penélope. Itaca, en ocasiones, pierde sus contornos, y como en imagen cinematográfica en disolución, se diluye para dejar ver el contorno claro, superimpuesto, de otra isla de sobra conocida por la autora.

La interacción entre los diferentes planos temporales le dan un carácter único a Viajes. Tejiendo su propio canto para protegerlo del paso inexorable del tiempo, la poeta lo hace prisionero de las páginas de su libro. Podemos colocarnos en el espacio vital de la autora, en su presente creando el poemario, y en el de Penélope, «la del quehacer nocturno», rememorando en presente su pasado feliz junto a Ulises. La multiplicidad de espacios temporales le permite a Juana Rosa Pita y a nosotros deambular de uno a otro, porque todos están armoniosamente relacionados.

A medida que nos adentramos en el libro, sentimos que hay otro tiempo que no puede deternerse, que se impone a todos los tiempos y que inexorablemente nos aprisiona en él, aunque no lo sintamos; un presente del que a menudo no tomamos conciencia:

Tejiendo la marea entre las islas ¿qué voces silenció el fragor del tiempo?

Salvo la soledad que vuela dentro

tal parece que nadie vive... ${ }^{47}$

\footnotetext{
45 Juana Rosa Pita, Ibid., p. 43.

${ }^{46}$ Juana Rosa Pita, Ibid., p. 87.

47 Juana Rosa Pita, Ibid., p. 85.
} 
Presente y pasado unidos en el mito, que es Penélope-Juana Rosa Pita en sus incesantes Viajes, están precisamente entrelazados en esta mitificación arquetípica, que es uno de los mejores logros de nuestra poesía.

Dios como arquetipo matiza algunas directrices ascendentes en MERCEDES GARCIA Tudurí. El exilio forma para ella parte de su mística, que está unida al amor a la tierra que no puede olvidar, y como árbol trasplantado afirma que «no olvida aquella savia / ni aquella luz olvida» ${ }^{48}$. Por ese motivo, su misticismo es nacionalista, patriótico, y su búsqueda arquetípica conjuga a Dios con la Patria, de modo muy tradicional en su contenido y en su forma.

Esta dirección religiosa y mística la sigue AMELIA DEL CASTILlo, que en Cauce de tiempo logra la poetización del momento en que el ser humano toma conciencia de su destino último. Al enfrentarse al sino ineludible, toma un camino introspectivo. De esa forma, en la búsqueda de sí misma trata de llegar a Dios. Su mirada va a dirigirla hacia el pasado, al mismo tiempo que hacia adentro, en dirección a su propio espíritu. Trata de llegar a sus orígenes, como si allí fuera a encontrar la respuesta definitiva: «Me iré en el viaje de los siglos / hasta el principio de mi paso» ${ }^{49}$. Regresa a su niñez y retoma el camino: "otra vez niña / hasta tu lado» ${ }^{50}$. Su subjetividad se complementa con una delicadeza espiritual que toma cuerpo en un verso sencillo y de gracia coloquial.

Ese retrotraerse hacia el pasado por el camino del recuerdo se materializa en poemas que son en ocasiones sueños, visiones intangibles inmersas en una atmósfera evidentemente romántica:

Te vi muy lejos...

Allá donde la sombra es blanca, allá donde se queda el tiempo ${ }^{51}$

$\mathrm{La}$ «sombra blanca», que corresponde en este caso a la imagen materna, se dibuja en un espacio fuera del tiempo, distancia insalvable. En ocasiones, la sombra es un desdoblamiento del yo. En el poema «Soliloquio» se dirige a ella rogándole, pero otras veces la contempla, junto a ella, en un pasado feliz. No falta de nuevo la súplica: «Déjame en ti vaciarme» ${ }^{52}$, como si quisiera que fuera el molde que contuviera la sustancia que la materializa. Sombra que es también arquetipo y presencia de Dios:

${ }^{48}$ Mercedes García-Tudurí, Andariega de Dios. Tiempo de exilio (N. J.: Senda Nueva de Ediciones, 1983), p. 58.

49 Amelia del Castillo, Cauce de tiempo (Miami: Ultra Graphics Corp.), p. 12.

50 Amelia del Castillo, Ibid., p. 12.

51 Amelia del Castillo, Ibid., p. 17.

52 Amelia del Castillo, Ibid., p. 31. 
Te siento, Dios, en cada vuelta de mi sombra, en cada sueño que te sueña y te busca ${ }^{53}$.

Finalmente, la poesía cubana busca un arquetipo último, que en ANGEL CUADRA, sin abandonar Patria e Isla, llega al concepto absoluto del Hombre como abarcador de todo lo humano. «Tiempo del hombre» es un largo poema de tono profético en el que Angel Cuadra va creando toda una cosmología. En ella describe la historia del hombre visto a través del Tiempo, entendido este último como un absoluto. El poema se inicia trasladándonos a un momento anterior a la Creación, donde las miradas del hombre aún eran «el asunto del polvo» ${ }^{54}$, insustancialidad, para casi inmediatamente llevarnos a un futuro completamente fuera de nuestro alcance en el que el Hombre resolverá «el enigma de todas las estrellas» ${ }^{55}$. Es un viaje en tiempo, de la nada al cosmos. El arquetipo traspasa los límites de Dios, viajero del tiempo y del espacio. Pero es también un tiempo ético, en el que él fundará el bien sobre los siglos; es decir, el bien sobre el tiempo. El autor tiene fe en que la inteligencia humana lo conducirá a ese momento utópico de comprensión que traerá la paz a todo el género humano:

Que vendrá el tiempo del amor

igual que un velo inmenso de rocío

Será el tiempo de la paz,

donde por fin la palabra «hombre»

sea como una deidad viva ${ }^{56}$.

Pero la quimérica utopía está aún muy lejos de la realidad. En un poemario publicado dos años después del anterior, el fondo intrahistórico del momento que vive el hombre que es él, queda al descubierto en «Escena repetida»:

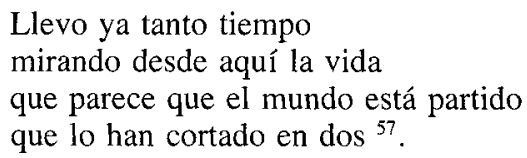

\footnotetext{
${ }^{53}$ Amelia del Castillo, Ibid., p. 33.

${ }_{54}$ Angel Cuadra, Tiempo del hombre (Madrid: Hispanova de Ediciones, 1977), p. 31.

55 Angel Cuadra, Ibid., p. 31.

${ }^{56}$ Angel Cuadra, Ibid., pp. 36-37.

57 Angel Cuadra, Poemas en correspondencia (Washington-Miami: Solar, 1979), p. 52.
} 
De observador del hombre en el tiempo pasa a ser hombre que observa la vida. Colocado en el «desde aquí» de su circunstancia, la contempla desde un tiempo real cuya duración expresa en el primer verso: «Llevo ya tanto tiempo». Su mirar, que comenzó en el pasado y que se ha prolongado en un tiempo que continúa aún en el momento en que escribe el poema, lo lleva a una concepción distorsionada, en la que el mundo es visto dividido, hendido, fraccionado. Esta percepción de Angel Cuadra corresponde a las categorías de tiempo y espacio que representa el destierro, que el poeta supera en el conjunto de su obra creadora con una actitud esperanzadora donde el Hombre es el supremo arquetipo*.

* Después de terminado este artículo fueron publicados dos tomos de la colección de Antologías de Felipe Lázaro sobre la poesía cubana escrita fuera de Cuba: Poetas cubanos en España. Editorial Betania. Madrid, España, 1988; Poetas cubanos en Nueva York. Editorial Betania, Madrid, España, 1988. Estos libros y un tercer tomo en preparación: Poetas cubanos en Miami, deben ser lectura obligatoria para todo aquel interesado en la poesía cubana escrita fuera de Cuba. 